\title{
(087-090) Proposal to treat the use of a hyphen in the name of a fossil-genus as an orthographical error
}

Committee on Fossils: Heidi Anderson, David J. Batten, David J. Cantrill, Christopher Cleal, Susanne Feist-Burkhardt, Robert A. Fensome, Martin J. Head (Chair), Patrick S. Herendeen (Secretary), Carlos Jaramillo, Jiří Kvaček, Stephen McLoughlin, Judith E. Skog, Masamichi Takahashi \& Reed Wicander

Secretary and author for correspondence: Patrick S. Herendeen, Chicago Botanic Garden, 1000 Lake Cook Road, Glencoe, Illinois 60022, U.S.A.; pherendeen@chicagobotanic.org

DOI http://dx.doi.org/10.12705/644.31

The Nomenclature Committee on Fossils has been dealing with numerous conservation proposals for names of fossil-genera that originally contained a hyphen (Doweld in Taxon 62: 638-642. 2013). Doweld correctly indicated that Art. 60.9 in the International Code of Nomenclature for algae, fungi, and plants (the Melbourne Code, McNeill \& al. in Regnum Veg. 154. 2012) allows removal of hyphens from epithets, but that Art. 60 Note 3 excludes generic names with hyphens from such orthographical correction. Although Doweld uncovered no fewer than 23 generic names that were published with a hyphen, the Committee on Fossils suspects that others exist in the early literature. Hyphenating generic names was a common practice among palynologists and paleobotanists prior to the inclusion of fossils in the main body of the International Code of Botanical Nomenclature at the Montreal Congress in 1959. Before this, beginning with the Cambridge Congress in 1930, a separate appendix governing the names of fossils was provided. The 1961 Code (Lanjouw \& al. in Regnum Veg. 23. 1961) indicated that names of fossil taxa were to be considered and treated no differently from the names of extant organisms covered under the Code. Since that time, the use of hyphens in names of fossil plants and palynomorphs was essentially discontinued and largely forgotten, such that compendia including Andrews (in Geol. Surv. Bull. 1300. 1970), for fossil plants, and Jansonius \& Hills (in Genera File of Fossil Spores and Pollen, Special Publ., Dept. Geol., Univ. Calgary: 4811 cards. 1976-1990), for plant microfossils, treated the names as if the hyphens were not part of the original spellings. Although hyphenated specific epithets were common for extant taxa, in the case of the names of fossils, hyphens were used primarily in generic names to suggest taxonomic affinity (e.g., Abies-pollenites), to offset a suffix indicating the type of fossil organ being named (e.g., Valvisi-sporites), or to combine two genera (e.g., Poa-Cordaites). These hyphenated forms of the names have been out of general use for at least the past 55 years. However, under the Code they take priority over the de-hyphenated variants unless the latter are conserved, an action that Doweld is proposing.

Herein we offer an alternative approach. Dealing with these names collectively through orthographical correction, rather than by laborious and piecemeal conservation and consequent inflation of the list of Conserved and Rejected Names of Genera and Subdivisions of Genera (Appendix III of the Code; see Wiersema \& al. in
Regnum Veg. 157. 2015), is a more efficient and enduring solution, and will eliminate uncertainty over the treatment of these names and their contained species. Therefore, we propose modifications to the Code such that use of a hyphen in the name of a fossil-genus is treated as an error to be corrected by deletion of the hyphen. This will circumvent the need to conserve the numerous de-hyphenated names against unused hyphenated forms. We propose changes to Art. 60 of the Code to allow this correction, and the addition of a phrase in Art. 20 to add clarity to the naming of fossil-genera.

(087) Amend Art. 60.9 as follows (new text in bold):

"60.9. The use of a hyphen in a compound epithet is treated as an error to be corrected by deletion of the hyphen. A hyphen is permitted only when the epithet is formed of words that usually stand independently, or when the letters before and after the hyphen are the same (see also Art. 23.1 and 23.3). The use of a hyphen in the name of a fossil-genus is in all cases treated as an error to be corrected by deletion of the hyphen."

(088) Amend Art. 60 Note 3 as follows (new text in bold):

"Note 3. Art. 60.9 refers only to epithets (in combinations), not to names of genera (fossils excepted) or taxa in higher ranks; a nonfossil generic name published with a hyphen can be changed only by conservation (Art. 14.11; see also Art. 20.3)."

(089) Add the following new Example after Art. 60 Note 3: "Ex. 27bis. "Cicatricosi-sporites" R. Potonié \& Gelletich (1932) and "Pseudo-Araucaria" Fliche (1896) are names of fossil-genera. They are treated as errors to be corrected by deletion of the hyphen to Cicatricosisporites and Pseudoaraucaria, respectively."

In order to fully clarify the naming of fossils, we also propose the addition of a cross-reference in Art. 20.3.

(090) Amend Art. 20.3 as follows (new text in bold):

"20.3. The name of a genus may not consist of two words, unless these words are joined by a hyphen (but see Art. 60.9 for names of fossil-genera)." 